\title{
Vascular to Alveolar Leak of Iron Dextran (120 kD) in the Immature Ventilated Rabbit Lung
}

\author{
BENGT ROBERTSON, GERTIE GROSSMANN, ALAN JOBE, MACHIKO IKEGAMI, \\ ANDREA PETTENAZZO, AND STEVEN SEIDNER
}

Karolinska Institute, Department of Pediatrics [B.R., G.G.J, St. Görans Children's Hospital, Stockholm, Sweden, and Department of Pediatrics [A.J., M.I., A.P., S.S.], Harbor-UCLA Medical Center, Torrance, California 90509

\begin{abstract}
Rabbit fetuses were delivered by hysterotomy on day 27 or 28 of gestation. Immediately after birth, the animals were tracheotomized and received by intravenous injection $0.2 \mu \mathrm{Ci}$ radiolabeled albumin and 11 $\mathrm{mg}$ iron dextran in $0.2 \mathrm{ml}$ saline. The newborn rabbits then were ventilated artificially with a tidal vol of $12 \mathrm{ml} / \mathrm{kg}$ for 5-20 min. One group of nonventilated animals served as controls. At the end of the experiment, one lung was lavaged via the airways and the other was fixed for histologic examination. The recovery of labeled albumin and iron dextran in the lavage fluid was quantified. Iron dextran complexes were easily identified in the lung sections by staining with Prussian blue. Iron dextran accumulated in the airspaces of animals delivered on day 27 (about $4 \%$ of the injected dose during 10-20 min of ventilation). The albumin leakage was slightly higher than that of the dextran, a result consistent with different mol wt of the markers. The vol density of leaking alveoli in histologic sections increased with time, from 0 at birth to a mean value of 0.36 after $20 \mathrm{~min}$ of ventilation. The leakage starts as a focal event, gradually involving more and more terminal airspaces. In the histologic sections, there was no indication of a significant leakage at the bronchiolar level, although the epithelium of terminal and preterminal airways was clearly injured in all ventilated animals. (Pediatr Res 25:130-135, 1989)
\end{abstract}

Permeation of fluid and protein into the alveoli is an important factor in the pathogenesis of the neonatal respiratory distress syndrome, especially as the pulmonary edema fluid contains inhibitors of pulmonary surfactant function $(1,2)$. Lung leakage of albumin has been quantified in animal models of respiratory distress syndrome, such as prematurely delivered lambs $(3,4)$ or rabbits $(5)$. The leakage of albumin was inversely related to gestational age (4). In immature lungs, it can be reduced significantly by antenatal administration of corticosteroids (6), thyrotropin-releasing hormone (7), or treatment with exogenous surfactant before the onset of ventilation $(3,5)$. Postnatal leakage of macromolecules other than albumin has not been quantified in immature neonatal lungs, nor has the site of leakage been identified. In the present experiments in preterm newborn rabbits,

Received April 7, 1988; August 30, 1988.

Correspondence and reprint requests Bengt Robertson, M.D., Department of Pathology St. Görans Hospital, S-112 81 Stockholm, Sweden.

Supported by Grant HD-12719 from the Department of Health and Human Sciences, The Swedish Medical Research Council (Project No. 3351), The Swedish National Association against Heart and Chest Diseases (including a travel grant to B.R.), and The Research Funds of the Karolinska Institute. we studied by morphometric techniques the lung leakage of 120$\mathrm{kD}$ iron dextran and correlated the iron dextran leak with the albumin leak. The permeation of iron dextran into the airspaces could easily be demonstrated by histologic techniques previously not applied for this particular purpose.

\section{MATERIALS AND METHODS}

Reagents. Iron dextran (Sigma Chemical Co., St. Louis, MO) was dialyzed in a $10-\mathrm{kD}$ molecular exclusion dialysis tubing against $0.9 \% \mathrm{NaCl}$. The iron dextran had an apparent $\mathrm{M}_{\mathrm{r}}$ of 120 $\mathrm{kD}$ as determined by high performance liquid chromatography, using a Sepharose 6 sizing column (Pharmacia Fine Chemicals, Piscataway, NJ) and dextran mol wt standards. Bovine monomer standard albumin (Miles Biochemicals, Elkhart, IN) was iodinated using chloramine $\mathrm{T}$ and extensively dialyzed before use (3).

General design of experiments. Immature newborn rabbits were delivered by hysterotomy either on day 27 or 28 of gestation (term $=31$ days) after the pregnant doe was anesthetized with intravenous pentobarbital and ketamine (approximate doses 20 and $10 \mathrm{mg} / \mathrm{kg}$, respectively). During the operation, the doe received $100 \%$ oxygen by face mask. The abdominal wall was anesthetized with $1 \%$ lidocaine, and the uterus was exposed. The fetuses were delivered sequentially, anesthetized with $10 \mathrm{mg} / \mathrm{kg}$ ketamine and $1 \mathrm{mg} / \mathrm{kg}$ acepromazine given by intraperitoneal injection, weighed, and immediately tracheotomized. The newborn rabbits then were injected, via an external jugular vein, with $0.2 \mathrm{ml}$ of a $0.9 \% \mathrm{NaCl}$ solution that contained $11 \mathrm{mg}$ iron dextran and $0.2 \mu \mathrm{Ci}$ of ${ }^{125} \mathrm{I}$-albumin. The tracheal tube was connected to a 0.5 -liter anesthesia bag, delivering $100 \%$ oxygen, and the neonate was ventilated manually until the chest movements indicated adequate expansion of the lungs; this usually required five slow ventilatory cycles to peak insufflation pressures of 30 to $35 \mathrm{~cm} \mathrm{H}_{2} \mathrm{O}$.

One group of animals was killed immediately after the intravascular injection and initial ventilation. The endotracheal tubes of the other animals were connected to a multiple ventilatorplethysmograph system that permitted the regulation of the peak inspiratory pressure used to ventilate each animal (6). Body temperature was controlled at $37^{\circ} \mathrm{C}$ with a circulating water bath. The initial ventilator settings for each animal were: peak inspiratory pressure, $35 \mathrm{~cm} \mathrm{H}_{2} \mathrm{O}$; end-expiratory pressure, $0 \mathrm{~cm} \mathrm{H} \mathrm{H}_{2} \mathrm{O}$; rate, 40 breaths/min; inspiratory time, $0.7 \mathrm{~s}$; and oxygen, $100 \%$. This style of ventilation will result in effective gas exchange in rabbits of this gestational age (6). Tidal vol were recorded with a pneumotachometer that was moved between the individual plethysmographs, and differential pressure was measured and integrated to vol using a Validyne pressure transducer and electronics (Validyne Engineering Corp., Springfield, NJ). Peak in- 
spiratory pressures only were adjusted to yield an approximate tidal vol of about $12 \mathrm{ml} / \mathrm{kg}$ body wt. Lung-thorax compliance was defined as the quotient between tidal vol and peak inspiratory pressure.

Groups of 27-day gestation rabbits were killed before mechanical ventilation ( 0 time) and after 5,10 , and 20 min of ventilation with an intracerebral injection of $2 \%$ lidocaine which caused immediate cardiac arrest. The chest was opened, and blood samples were drawn from the heart into heparinized syringes. The blood was used for $\mathrm{Hb}$ analysis (8) and measurements of the ${ }^{125}$ I-albumin and iron dextran contents.

The 28-day gestation rabbits were studied as were the other rabbits, except groups were killed only at 0 or $10 \mathrm{~min}$. We anticipated that the lungs of these animals would leak less than those of animals delivered on day 27 . However, we wanted to combine data from day 27 and day 28 animals ventilated for the same period of time $(10 \mathrm{~min})$ to evaluate whether variations of dextran leak would correlate with lung compliance.

Processing of lungs. After opening of the chest and obtaining blood samples, the left main bronchus was tied with silk sutures. The right lung was then washed in situ with normal saline via the tracheal tube. The right lung was filled to total capacity by visual inspection; saline was flushed in and out of the airways three times. This procedure was performed altogether five times, and the five washes were pooled for quantification of labeled albumin and iron dextran. The washed right lung was then removed, weighed, and homogenized in distilled water. Aliquots of the homogenate were assayed for iron dextran and ${ }^{125} \mathrm{I}$-albumin. Part of the homogenate was centrifuged at $27,000 \times g$, and the resulting supernatant was used for analysis of $\mathrm{Hb}$. The $\mathrm{Hb}$ associated with the lung homogenate was assumed to be derived from intravascular blood, and the blood-associated radioactivity was subtracted from that measured for each lung $(3,5)$. Recoveries of labeled albumin were expressed as a percentage of injected dose.

Quantification of iron dextran. Samples were assayed for iron dextran with Ferene $\mathrm{S}$ (Sigma Chemical Co.) in an assay adapted from the clinical measurement for serum iron (9). To a diluted aliquot of each sample were added $2 \mathrm{ml}$ of an acetate/ascorbic acid reagent $(1 \mathrm{M}$ acetate buffer at $\mathrm{pH} 4.5$ containing $0.13 \mathrm{M}$ thiourea, $0.06 \mathrm{M}$ ascorbic acid, and $0.5 \%$ Triton-100), which was then allowed to stand for $20 \mathrm{~min}$. Then $0.1 \mathrm{ml}$ of a solution of $180 \mathrm{mg}$ Ferene $S$ in $10 \mathrm{ml}$ water was added; the mixture was boiled for $10 \mathrm{~min}$, and the OD was read at $595 \mathrm{~nm}$. Standard curves were prepared using the iron dextran solutions used for the injections of the rabbits. For samples containing blood, the $\mathrm{Hb}$ content was measured with Drabkin's solution, and the small effect of blood on the assay for iron dextran was subtracted.

Morphologic examination. The whole left lung was fixed by immersion in Carnoy's fixative (ethanol:chloroform:acetic acid, $60: 30: 10$ ). Paraffin sections ( $3 \mu \mathrm{m}$ thick) from the lower lobes were stained with hematoxylin and eosin or with Prussian blue, and examined microscopically with particular reference to the extent of bronchiolar epithelial lesions induced by the period of artificial ventilation (10), and to the presence of iron dextran in the intravascular, interstitial, alveolar, bronchiolar, and lymphatic spaces. To quantify morphologically the leak of dextran into the airspaces, we used conventional point-counting, and determined the vol density of alveoli showing the iron-label in the lumen, using the total parenchyma as reference vol. To avoid bias, the histologic sections were coded before microscopic examination.

Statistical analysis. The data are given as mean \pm SD when distributed normally, otherwise as median and range. An ANOVA was used to identify differences between groups, and the Student-Newman-Keuls multiple comparison procedure was used subsequently to assign significance. Differences in the morphometric measurements between groups were evaluated by the Wilcoxon two sample test (two tailed). Measurements of iron dextran recovery were linearly regressed against those for ${ }^{125} \mathrm{I}$ albumin recovery and against the mean peak inspiratory pressures applied to ventilate the animals, using the method of least squares.

\section{RESULTS}

Lung mechanics. The number of animals in each group, body wt, peak insufflation pressures, tidal vol, and lung-thorax compliance values are summarized in Table 1 . In neonates studied on day 27 of gestation, body wt was lower, and the insufflation pressure needed to maintain a tidal vol of about $12 \mathrm{ml} / \mathrm{kg}$ body wt was significantly higher than in animals delivered on day 28 $(p<0.001)$

Bronchiolar epithelial lesions. HE-stained lung sections from neonates delivered on day 27 and killed immediately after the initial manual ventilation showed no $(n=5)$ or focal $(n=2)$ necrosis and desquamation of the bronchiolar epithelium (Fig. $1 A$ ). The incidence and severity of such epithelial lesions increased with the duration of artificial ventilation. All but one of the neonates ventilated for 5 min showed a moderate amount of necrotic epithelium in the airways; in the exceptional animal, the airway epithelium was intact. In animals ventilated for 10 or $20 \mathrm{~min}$, the bronchiolar epithelial lesions were consistently more abundant and severe (Fig. $1 B$ ). In animals delivered on day 28 and ventilated for $10 \mathrm{~min}$, the epithelial lesions were much less prominent.

Leakage of iron dextran. Iron-labeled particles were found in the lungs of all animals delivered on day 27 , but the location of the material differed between the groups. In animals killed immediately after the intravenous injection, the iron particles were only in the blood vessels, usually in veins (Fig. $2 A$ ). Accumulation of iron particles in the interstitial space (especially around veins) and in the lymphatics was prominent only in animals killed after 10 or $20 \mathrm{~min}$ of ventilation (Fig. $2 B$ ). In animals killed after 5 min and at subsequent intervals, there was an increasing amount of iron particles in the peripheral airspaces (Fig. $3 A$ and $B$ ). Areas with seemingly incipient leakage were scrutinized with particular reference to the alveolar and bronchiolar epithelium. There were clear indications that the leak occurred in alveoli with disrupting epithelium; nonleaking alveoli with little epithelial injury were frequently observed next to leaking alveoli with widely destroyed epithelium (Fig. $3 A$ ). No such pattern was present in bronchioles. Damaged mucosal surfaces were found without significant accumulation of iron particles in the airway (Fig. $4 A$ ); conversely, comparatively large amounts of iron particles were present in some bronchioles with intact epithelium (Fig. $4 B$ ). The morphometric data, summarized in Table 2 , indicated that the vol density of leaking alveoli increased with the period of artificial ventilation $(r=0.76 ; p<0.001)$. Very few leaking alveoli could be identified in animals delivered on day 28, irrespective of whether they were killed immediately after the period of manual ventilation or after $10 \mathrm{~min}$ of artificial ventilation (data not shown).

Leakage of dextran and albumin. In neonates delivered on day 27 , the amount of iron dextran recovered in the wash increased with the duration of artificial ventilation, from a median of $0.11 \%$ in animals ventilated only manually, to $2.63 \%$ after $20 \mathrm{~min}$ of artificial ventilation $(r=0.49 ; p<0.02)$ (Table $3)$. On day 28 , the iron dextran leak into alveolar spaces was much less prominent, with a median value of $0.24 \%$ after 10 min of ventilation (Table 3). The amount of labeled albumin recovered in the wash also increased with the duration of ventilation on day $27(r=0.50 ; p<0.02)$ and was significantly lower on day 28 (Table 4). There was a highly significant correlation between the magnitude of the leak measured with ${ }^{125}$ I-albumin and iron dextran (Fig. $5 A$ ). The slope differed from 1.0 by about 
$20 \%$ indicating that somewhat more albumin than iron dextran was recovered by alveolar wash.

The amount of iron dextran in total lung of animals delivered on day 27 increased from a median of $0.51 \%$ in neonates ventilated only manually to $5.26 \%$ after $20 \mathrm{~min}$ of artificial ventilation $(r=0.62 ; p<0.002)$ (Table 3 ). In animals delivered on day 28 the median level of iron dextran was $0.64 \%$ in manually ventilated animals and $0.72 \%$ after $10 \mathrm{~min}$ of artificial ventilation (Table 3). The albumin leak during corresponding periods increased from a median of 0.44 to $6.33 \%$ in day 27 animals $(r=0.68 ; p<0.001)$, and from 0.13 to $0.61 \%$ in animals delivered on day 28 (Table 4). There was a strong correlation between the inspiratory pressures needed to ventilate the lungs and the leakage of iron dextran (Fig. $5 B$ ).

\section{DISCUSSION}

In the surfactant-deficient neonatal lung, epithelial disruption occurs within a few min of ventilation. The presence of such lesions in the lung of a newborn infant may even have forensic

Table 1. Duration of artificial ventilation and number of experimental animals in each group*

\begin{tabular}{|c|c|c|c|c|c|c|}
\hline $\begin{array}{l}\text { Gestational } \\
\text { age (days) }\end{array}$ & $\begin{array}{l}\text { Duration } \\
\text { of } \\
\text { ventilation } \\
\text { (min) }\end{array}$ & $n$ & BW (g) & $\begin{array}{c}\text { Peak insufflation } \\
\text { pressure } \\
\left(\mathrm{cm} \mathrm{H}_{2} \mathrm{O}\right)\end{array}$ & $\begin{array}{c}\mathrm{V}_{\mathrm{T}} \\
(\mathrm{ml} / \mathrm{kg})\end{array}$ & $\begin{array}{c}\mathrm{C} \\
\left(\mathrm{ml} / \mathrm{cm} \mathrm{H}_{2} \mathrm{O} \cdot \mathrm{kg}\right) \\
\end{array}$ \\
\hline 27 & $\begin{array}{r}0 \\
5 \\
10 \\
20\end{array}$ & $\begin{array}{l}6 \\
5 \\
5 \\
6\end{array}$ & $\begin{array}{l}31.6 \pm 3.9 \\
28.6 \pm 2.9 \\
28.2 \pm 4.3 \\
29.1 \pm 2.5\end{array}$ & $\begin{array}{l}34.2 \pm 5.4 \\
34.2 \pm 2.9 \\
33.5 \pm 2.5\end{array}$ & $\begin{array}{l}11.4 \pm 1.3 \\
13.4 \pm 3.0 \\
12.8 \pm 2.7\end{array}$ & $\begin{array}{l}0.34 \pm 0.04 \\
0.39 \pm 0.04 \\
0.39 \pm 0.10\end{array}$ \\
\hline 28 & $\begin{array}{r}0 \\
10\end{array}$ & $\begin{array}{r}5 \\
23\end{array}$ & $\begin{array}{l}38.0 \pm 3.8 \\
37.7 \pm 6.2\end{array}$ & $21.9 \pm 4.8$ & $12.3 \pm 1.4$ & $0.59 \pm 0.14$ \\
\hline
\end{tabular}

$*$ Body wt $(\mathrm{BW})$, peak insufflation pressure, tidal vol $\left(\mathrm{V}_{\mathrm{T}}\right)$, and lung-thorax compliance $(\mathrm{C})$. Values are given as mean $\pm \mathrm{SD}$.

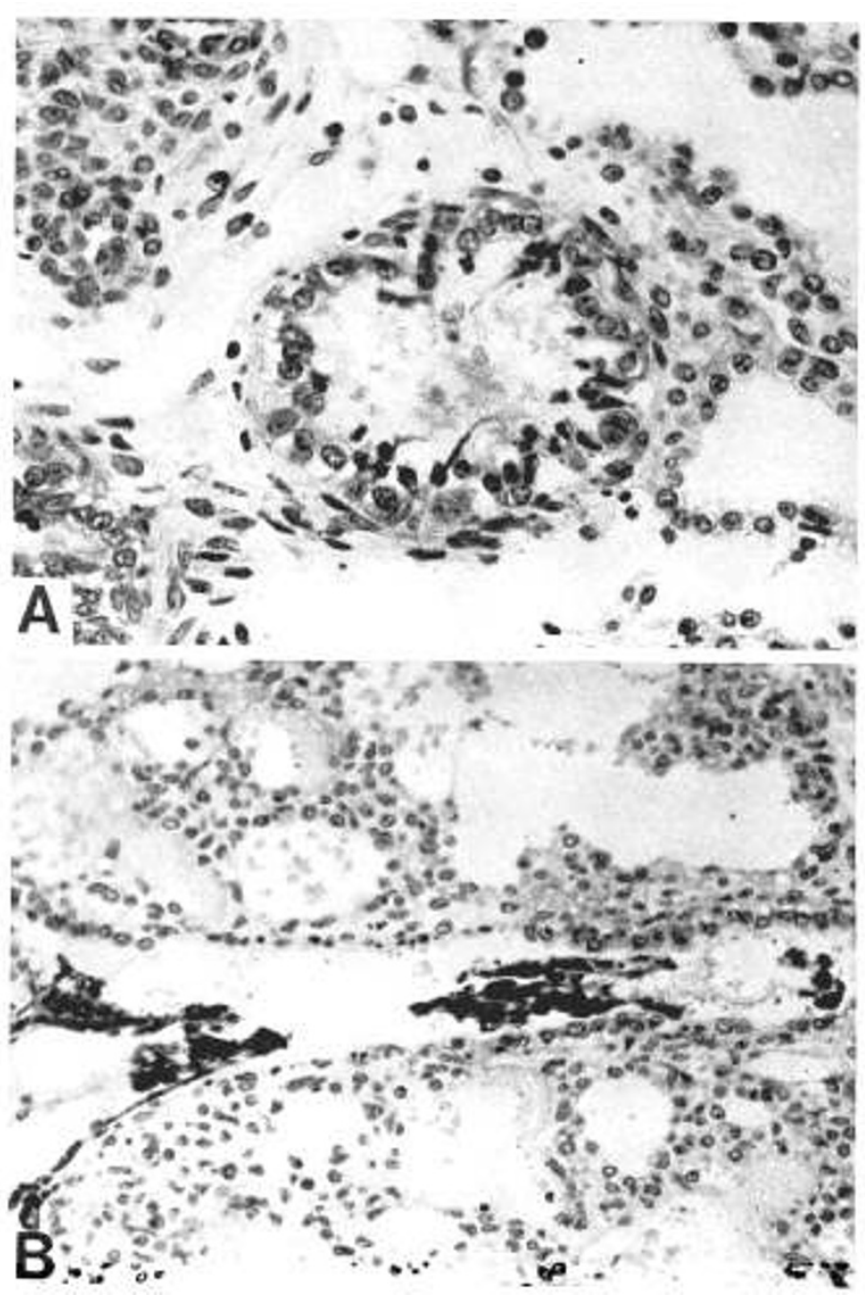

Fig. 1. Bronchiolar epithelial lesions induced by artificial ventilation in immature newborn rabbits delivered on day 27 of gestation. $A$, necrosis and desquamation of isolated epithelial cells in animal killed immediately after the period of manual ventilation $(\mathrm{HE}, \times 450) . B$, prominent shedding of necrotic airway epithelium in animal ventilated for $20 \mathrm{~min}$ $(\mathrm{HE}, \times 280)$.
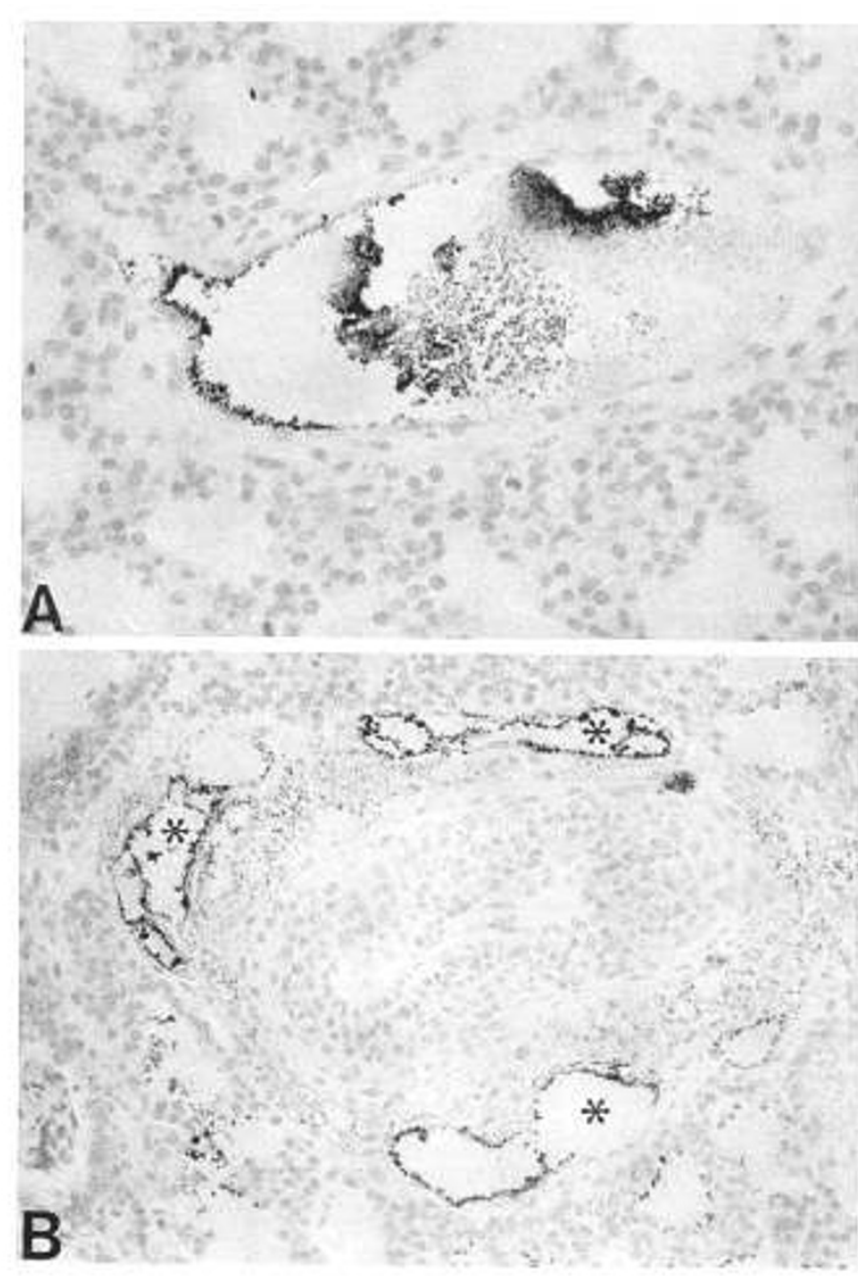

Fig. 2. Iron dextran visible as dark granules in intravascular and interstitial spaces of immature newborn rabbits delivered on day 27 of gestation. $A$, iron dextran in pulmonary vein; this animal was killed immediately after the period of manual ventilation (Prussian blue, $x$ 340). $B$, iron dextran in lymphatics $\left({ }^{*}\right)$ and in the interstitial space around a muscular pulmonary artery (Prussian blue, $\times 230)$. 


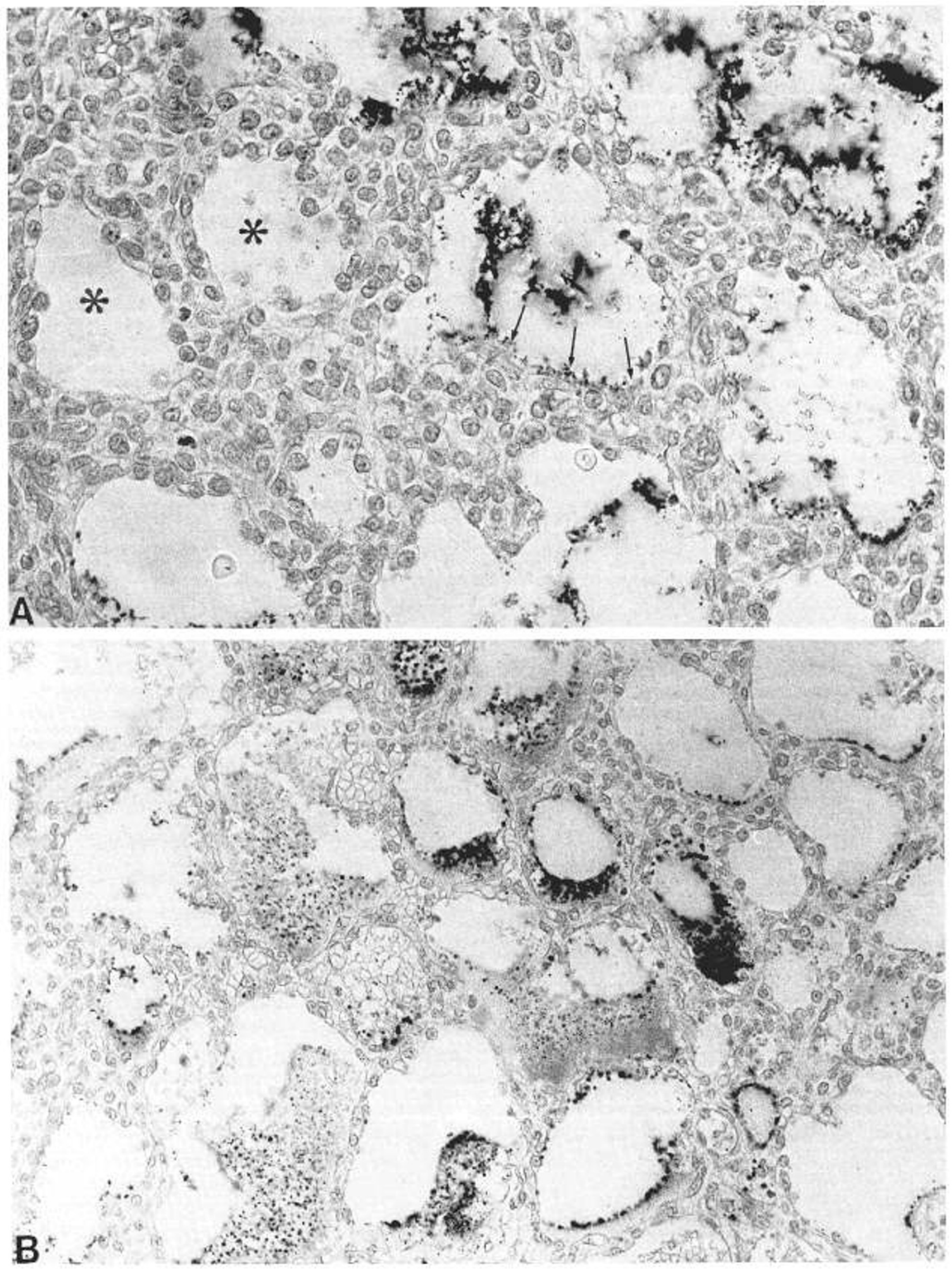

Fig. 3. Leakage of iron dextran in the airspaces of immature newborn rabbits, delivered on day 27 of gestation and subjected to mechanical ventilation. $A$, irregular leakage into the terminal airspaces of animal ventilated for $5 \mathrm{~min}$. Leaking alveoli with disrupted epithelium (e.g. small arrows) are seen next to nonleaking alveoli with less epithelial injury $\left(^{*}\right)$ (Prussian blue, $\times 590$ ). B, prominent leakage of iron dextran with flooding of some alveoli in animal ventilated for $20 \mathrm{~min}$ (Prussian blue, $\times 370$ ). 


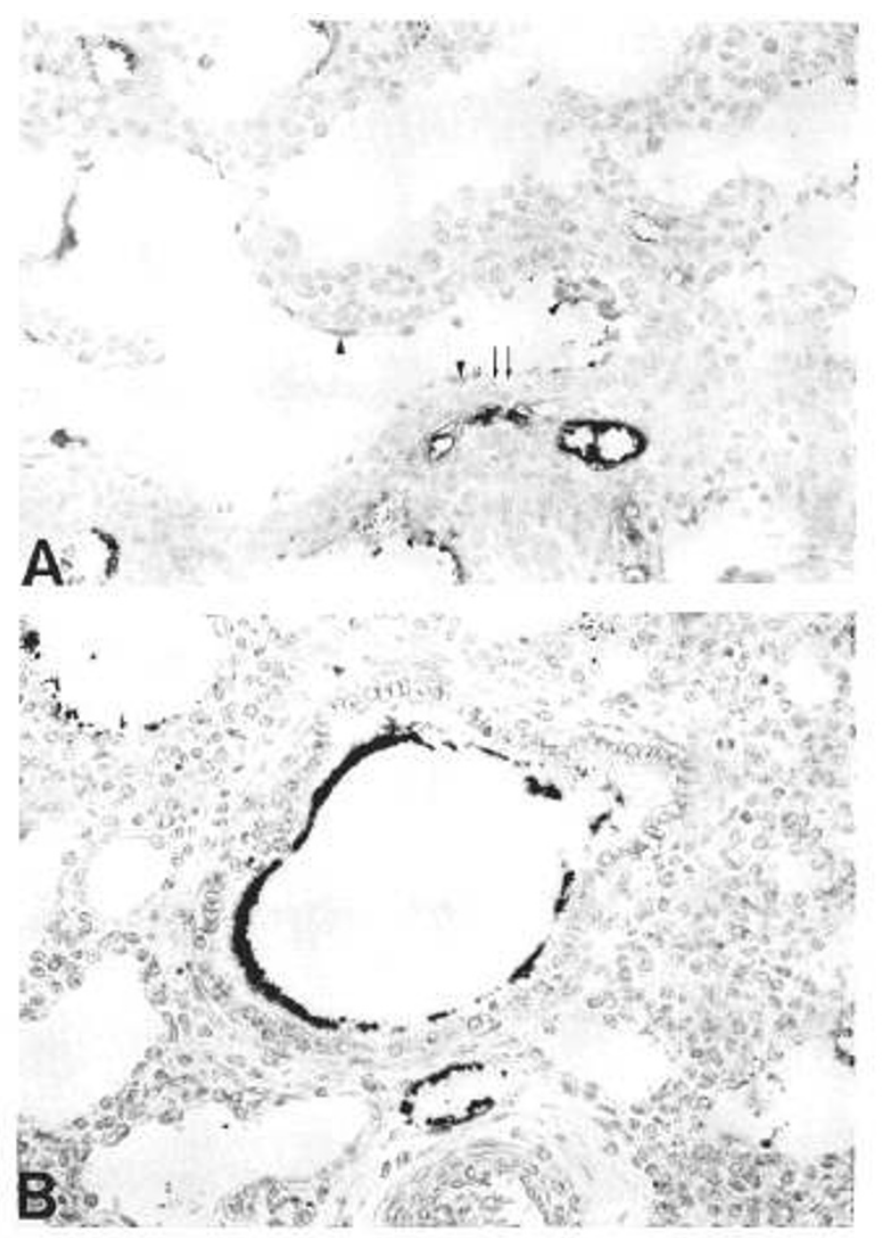

Fig. 4. Details of bronchioles from immature newborn rabbits, delivered on day 27 of gestation and subjected to mechanical ventilation for $10 \mathrm{~min}$. A, bronchiole with epithelial disruption (small arrows) and shedding (arrowheads), without significant concomitant leakage of iron dextran (Prussian blue, $\times 300$ ). $B$, bronchiole with largely intact epithelium but prominent accumulation of iron dextran in the lumen. The leakage probably occurred in more distal airspaces (Prussian blue, $x$ $310)$.

Table 2. Vol density of leaking alveoli in immature newborn rabbits delivered on day 27 of gestation

\begin{tabular}{ccc}
\hline $\begin{array}{c}\text { Duration } \\
\text { of } \\
\text { ventilation } \\
\text { (min) }\end{array}$ & Median & Range \\
\cline { 2 - 3 } & 0.001 & $0-0.1$ \\
5 & 0.08 & $0-0.44$ \\
10 & 0.20 & $0.04-0.50$ \\
20 & 0.35 & $0.29-0.46$ \\
\hline
\end{tabular}

* Values, obtained after various periods of artificial ventilation, are given as median and range.

implications because it proves, in an obscure case of perinatal death, that the baby has indeed been breathing or has been ventilated (11). In the present study, we found focal necrosis and desquamation of bronchiolar epithelium in animals that had been killed immediately after the brief period of manual ventilation. This rapidly developing lung injury is probably secondary to forces resulting from nonhomogeneous alveolar expansion, hyperexpansion of bronchioles during inspiration, and the pressures required to open the alveoli from the collapsed state. These opening forces occur during each ventilatory cycle unless the
Table 3. Leakage of iron dextran into alveolar wash and total lung in immature newborn rabbits delivered on day 27 or 28 of gestation*

\begin{tabular}{|c|c|c|c|c|c|}
\hline \multirow{3}{*}{$\begin{array}{l}\text { Gestational } \\
\text { age (days) }\end{array}$} & \multirow{3}{*}{$\begin{array}{l}\text { Ventilation } \\
(\min )\end{array}$} & \multicolumn{4}{|c|}{ Iron dextran leak (\%) } \\
\hline & & \multicolumn{2}{|c|}{ Alveolar wash } & \multicolumn{2}{|c|}{ Total lung } \\
\hline & & Median & Range & Median & Range \\
\hline \multirow[t]{4}{*}{27} & 0 & 0.11 & $0.06-0.31$ & 0.51 & $0.35-0.61$ \\
\hline & 5 & 1.56 & $0.28-3.16$ & 1.75 & $0.40-4.75$ \\
\hline & 10 & 4.17 & $0.58-8.93$ & 5.97 & $1.40-11.0$ \\
\hline & 20 & 2.63 & $1.12-9.00$ & 5.26 & $2.46-12.1$ \\
\hline \multirow[t]{2}{*}{28} & 0 & 0.25 & $0-0.56$ & 0.64 & $0.54-1.11$ \\
\hline & 10 & 0.24 & $0.05-6.10 \dagger$ & 0.72 & $0.32-8.15 \ddagger$ \\
\hline
\end{tabular}

* The measurements were obtained after various periods of artificial ventilation. Animals at time 0 were ventilated manually until the lungs were opened up and then were immediately killed (values are given as percentage of injected dose, median, and range).

$\dagger p$ versus 27 days, $10 \mathrm{~min}<0.01$.

$\ddagger p$ versus 27 days, $10 \mathrm{~min}<0.05$.

Table 4. Leakage of labeled albumin into alveolar wash and total lung in artificially ventilated immature newborn rabbits delivered on day 27 or day 28 of gestation, and in manually ventilated controls*

\begin{tabular}{|c|c|c|c|c|c|}
\hline \multirow{3}{*}{$\begin{array}{c}\text { Gestational } \\
\text { age (day) }\end{array}$} & \multirow{3}{*}{$\begin{array}{l}\text { Ventilation } \\
\quad(\min )\end{array}$} & \multicolumn{4}{|c|}{ Labeled albumin leakage (\%) } \\
\hline & & \multicolumn{2}{|c|}{ Alveolar wash } & \multicolumn{2}{|c|}{ Total lung } \\
\hline & & Median & Range & Median & Range \\
\hline \multirow[t]{4}{*}{27} & 0 & 0.36 & $0.25-0.41$ & 0.44 & $0.29-1.10$ \\
\hline & 5 & 2.18 & $0.43-3.90$ & 2.89 & $0.43-5.83$ \\
\hline & 10 & 5.38 & $0.89-10.3$ & 6.84 & $1.98-11.5$ \\
\hline & 20 & 3.25 & $1.72-10.6$ & 6.33 & $3.54-14.3 \dagger$ \\
\hline \multirow[t]{2}{*}{28} & 0 & 0.01 & $0-0.15$ & 0.13 & $0.02-0.69$ \\
\hline & 10 & 0.09 & $0.01-8.24 \ddagger$ & 0.61 & $0.01-11.2 \ddagger$ \\
\hline
\end{tabular}

* Same conditions as in Table 3 (values are given as percentage of injected dose, median, and range).

$\dagger p$ versus $5 \mathrm{~min}=0.05$.

$\ddagger p$ versus 27 days, 10 min $<0.01$.

alveoli are kept open by the application of an appropriate positive end-expiratory pressure (12). Scanning and transmission electron microscopic studies have revealed widespread disruption of bronchiolar epithelium in immature newborn rabbits, delivered at a gestational age of 27 days, after only $5 \mathrm{~min}$ of conventional intermittent positive pressure ventilation $(10,13)$. The development of such epithelial lesions can be prevented by treatment with surfactant at birth, before the onset of ventilation $(13,14)$.

The epithelial cells coating the alveoli and the conducting airways are linked by tight junctions. The pore equivalent radius of the lung epithelium may be transiently enlarged from about $0.6 \mathrm{~nm}$ to $3.5 \mathrm{~nm}$ during vigorous efforts to ventilate the lungs at birth (15), but the epithelial border remains impermeable to albumin and larger molecules unless cell junctions become disrupted. We found a significant leakage of iron dextran in all animals delivered after 27 days gestation and subsequently subjected to artificial ventilation. The degree of dextran leakage clearly increased with the duration of ventilation, and correlated with the pressures required to ventilate the lungs, i.e. presumably with the degree of surfactant deficiency and the extent of epithelial injury. A good correlation was also found between the leakage of iron dextran and that of albumin, indicating that the two parameters yield comparable information. However, the leakage of albumin was somewhat larger, which is explained by the difference in molecular weight (120 versus $69 \mathrm{kD}$ ).

The use of iron dextran as a marker faciliated the identification 


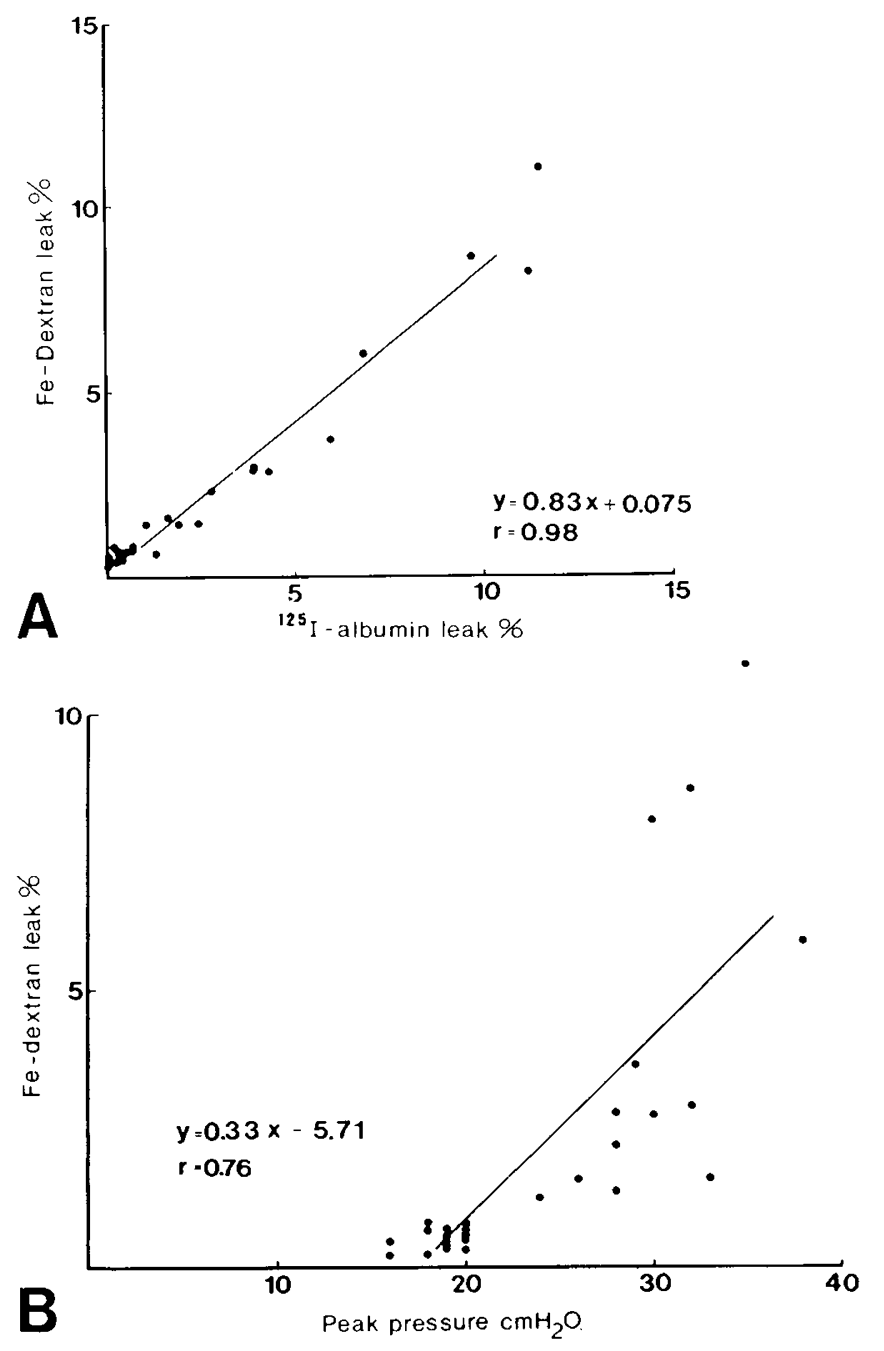

Fig. 5. Linear regression analyses of data from animals delivered on day 27 or 28 or gestation and ventilated for $10 \mathrm{~min}$. $A$, total lung leakage of labeled albumin versus that of iron dextran. $B$, peak insufflation pressure versus total lung leakage of iron dextran.

of leaking airspaces in the histologic sections. The pattern of leakage was usually not homogenous, and our morphometric data furthermore suggested that the leakage gradually involved an increasing number of airspaces during the 20 -min period of observation. Although our findings may not be conclusive, the distribution of iron dextran in the lungs clearly suggested that the major leak occurred at the alveolar rather than at the bronchiolar level, presumably from alveolar capillaries in areas of epithelial desquamation as illustrated in Figure $3 A$. The iron dextran also seemed to leak through the walls of pulmonary veins into the surrounding loose connective tissue. No such leak was demonstrated in the walls of muscular pulmonary arteries, but the lymphatics around these arteries were usually loaded with iron dextran in day 27 animals ventilated for $10 \mathrm{~min}$ or more; this probably reflects a drainage of the interstitial compartment.

The leakage gradually led to flooding of many airspaces with proteinaceous edema. However, also in lung sections from ani- mals ventilated for 20 min there was usually a large field to field variability, with flooded areas alternating with areas showing much less marker in the airspaces. Furthermore, in the latter areas, leaking alveoli with disrupted epithelium were observed next to nonleaking alveoli with seemingly intact epithelial lining. These observations are compatible with leakage due to epithelial lesions caused by irregular expansion patterns, reflecting regional variations in compliance, as explained above. Our "domino" concept of the process of leakage, starting as a focal event but involving a gradually increasing number of alveoli, is supported by the values for vol density of leaking alveoli shown in Table 2, especially as the morphometric data tallied with direct measurements of the amount of iron dextran entering the airspaces.

The size of the iron dextran complex $(120 \mathrm{kD})$ is close to that of the dimer form of the surfactant inhibitor protein $(110 \mathrm{kD})$ identified by Ikegami and coworkers $(1,2)$. This latter protein enters the airspaces of the immature neonatal lung after the onset of ventilation (3) and may, together with other leaking proteins (16), interfere with surfactant function, thereby aggravating the effects of an underlying surfactant deficiency. The leakage of iron dextran can be used, in experimental models, as convenient morphometric marker for the increased permeability that may be a central factor in the pathogenesis of neonatal respiratory distress syndrome.

\section{REFERENCES}

1. Ikegami M, Jobe A, Jacobs H, Lam R 1984 A protein from airways of premature lambs that inhibits surfactant function. J Appl Physiol 57:11341142

2. Ikegami M, Jobe A, Berry D 1986 A protein that inhibits surfactant in respiratory distress syndrome. Biol Neonate 50:121-129

3. Jobe A, Ikegami M, Jacobs H, Jones S, Conaway D 1983 Permeability of premature lamb lungs to protein and the effect of surfactant on that permeability. J Appl Physiol 55:169-176

4. Jobe A, Jacobs H, Ikegami M, Berry D 1985 Lung protein leaks in ventilated lambs: effect of gestational age. J Appl Physiol 58:1246-1251

5. Robertson B, Berry D, Curstedt T, Grossmann G, Ikegami M, Jacobs H, Jobe A, Jones S 1985 Leakage of protein in the immature rabbit lung: effect of surfactant replacement. Respir Physiol 61:265-276

6. Ikegami M, Berry D, ElKady T, Pettenazzo A, Seidner S, Jobe A 1987 Corticosteroids and surfactant change lung function and protein leaks in the lungs of ventilated premature rabbits. J Clin Invest 79:1371-1378

7. Ikegami M, Jobe AH, Pettenazzo A, Seidner SR, Berry DD, Ruffini L 1987 Effects of maternal treatment with corticosteroids, $\mathrm{T}_{3}, \mathrm{TRH}$, and their combinations on lung function of ventilated preterm rabbits with and without surfactant treatments. Am Rev Respir Dis 136:892-898

8. Bland RD, McMillan DD, Bressack MA, Dong L 1980 Clearance of liquid from lungs of newborn rabbits. J Appl Physiol 49:171-177

9. Artiss JD, Vinogradov S, Sak B 1981 Spectrophotometric study of several sensitive reagents for serum iron. Clin Biochem 14:311-315

10. Nilsson R, Grossmann G, Robertson B 1980 Bronchiolar epithelial lesions induced in the premature rabbit neonate by short periods of artificial ventilation. Acta Pathol Microbiol Scand [a] 88:359-367

11. Robertson B 1987 Pathology of neonatal surfactant deficiency. Perspect Pediatr Pathol 11:6-46

12. Nilsson R, Grossmann G, Robertson B 1980 Artificial ventilation of premature newborn rabbits: effects of positive end-expiratory pressure on lung mechanics and lung morphology. Acta Paediatr Scand 69:597-602

13. Grossmann G, Nilsson R, Robertson B 1986 Scanning electron microscopy of epithelial lesions induced by artificial ventilation of the immature neonatal lung: the prophylactic effect of surfactant replacement. Eur J Pediatr 145:361-367

14. Nilsson R, Grossmann G, Robertson B 1978 Lung surfactant and the pathogenesis of neonatal bronchiolar lesions induced by artificial ventilation. Pediatr Res 12:249-255

15. Egan EA, Olver RE, Strang LB 1975 Changes in non-electrolyte permeability of alveoli and the absorption of lung liquid at the start of breathing in the lamb. J Physiol (Lond) 244:161-179

16. Fuchimukai T, Fujiwara T, Takahashi A, Enhorning G 1987 Artificial pulmonary surfactant inhibited by proteins. J Appl Physiol 62:429-437 